\title{
Управление в сфере обращения с твердыми коммунальными отходами: современное состояние
}

\author{
Н.И. ПЛЯСКИНА, доктор экономических наук, Институт экономики \\ и организации промышленного производства СО РАН, Новосибирский \\ национальный исследовательский государственный университет. \\ E-mail: pliaskina@hotmail.com \\ В.Н. ХАРИТОНОВА, кандидат экономических наук, Институт экономики \\ и организации промышленного производства СО РАН, Новосибирск. \\ E-mail: kharit@ieie.nsc.ru
}

В статье дан сравнительный анализ состояния утилизации твердых коммунальных отходов (ТКО) в России и в экономически развитых странах, представлены оценки влияния системы управления обращения с отходами на эффективность утилизации ТКО, становление рециклинга как важнейшей отрасли вторичной переработки отходов. Показаны роль экологического права для участия бизнеса в решении экологических проблем обращения с отходами. Освещены административно-управленческие барьеры формирования рынка отходов в российской экономике.

Ключевые слова: твердые коммунальные отходы (ТКО), утилизация, рециклинг, экологическое право, управление, механизмы стимулирования

\section{Мировой опыт управления бытовыми отходами}

Проблема утилизации техногенных отходов давно и остро стоит во всем мире, особенно в крупных городах.

В ЕС сформировано экологическое право, регулирующее процессы образования, учета, переработки и утилизации отходов. Кроме того, существуют решения органов ЕС (например, Европейского суда) и другие документы, которыми страны-члены Союза могут руководствоваться при разработке национальных программ и политики в сфере ресурсопотребления и обращения с отходами.

Большинство стран ЕС приняли или планируют принять нормативные акты, регулирующие порядок захоронения отходов на полигонах, в законодательном порядке вводят мероприятия по раздельному их сбору. Лидерами являются Германия, Дания, Финляндия, Голландия. Во Франции более 10 лет действует 
закон, запрещающий сбор несортированных бытовых отходов, а в Нидерландах введен запрет на захоронение органических отходов. Постановления, запрещающие или ограничивающие захоронение на полигонах биоразлагаемых органических отходов, приняты в Австрии, Бельгии, Дании, Франции, Италии, Норвегии и ряде других стран.

Стратегия управления использованием отходов направлена на ресурсосбережение и сохранение окружающей среды за счет масштабного развития индустрии рециклинга. В развитых странах более $20 \%$ новых товаров производится из отходов или вторичных ресурсов материального производства [1].

В ряде стран переработка отходов признана важной экономической задачей государственного уровня, так как извлеченные из твердых отходов металлы могут обеспечить в значительных объемах национальные потребности в железе, алюминии, олове и др. Для ее решения разработана законодательная и правовая политика стимулирования рециклинга. Законы о рециклинге действуют более чем в 50 странах мира.

В странах Европы развивается система централизованного госрегулирования рециклинга, включающая поощрительные программы и жесткое нормирование доли отходов, подлежащих переработке. Предприятия несут ответственность за переработку выпущенной ими продукции и рациональное использование вторсырья. Так, Директива ЕС установила довести к 2019 г. долю переработки электрического и электронного лома в странах Европы до 65\%, а Директива о захоронении отходов запрещает захоронение использованных шин на полигонах.

В 2013 г. средний уровень переработки бумажных отходов в Европе достиг почти 72\% и лишь в 11 странах он не превышает 60\%. За 1998-2013 гг. общий объем собранной и переработанной бумаги превысил 57 млн т, при этом ее рециклинг увеличился на 45\% (18 млн т) [2]. Подавляющая часть макулатуры заготавливается из легкодоступных источников: промышленных, торговых и административных предприятий и учреждений. Организован сбор макулатуры и у населения.

Наиболее значимые результаты получены в Германии, где мощности свалок исчерпывались к 2000 г. Закон об отходах упаковки с учетом новой европейской директивы обязал предприятия принимать упаковку после ее использования и перерабатывать, 
сбор должен быть организован в непосредственной близости от мест возникновения отходов и охватывать всю территорию, с соблюдением квот утилизации - от $60 \%$ до $70 \%$.

Третьим лицом при выполнении этих обязательств выступила некоммерческая организация «Дуальная система Германии» (DSD). Она должна принимать и перерабатывать отходы от всех фирм, производящих и торгующих упаковочной продукцией, в том числе и не являющихся участниками DSD. Знак DSD - «зеленая точка» на произведенном товаре - официально подтверждает, что за прием и утилизацию упаковки производитель или фасовщик платит DSD лицензионный взнос, за счет которого и финансируются ее сбор, сортировка и переработка. Лицензионный взнос производителя отходов соответствует реальным затратам на утилизацию и рассчитывается с учетом вида отходов, их массы и объема. Организации по образцу DSD были созданы и в других развитых странах. В настоящее время в Европе ежегодно маркируются «зелёной точкой» около 460 млрд ед. упаковки, около 70 тыс. предприятий получили лицензию.

Набирают темпы переработка пластиковой и алюминиевой тары, стекла, восстановления шин легковых машин, электронного хлама, извлечения и утилизации опасных отходов из отживших своё транспортных средств, холодильников и другого оборудования. В настоящее время в странах ЕС 15\% шин для легковых машин произведены из вторичного сырья, при этом производственные издержки на $20 \%$ ниже, чем при изготовлении из первичного сырья.

Решая общую для ЕС задачу кардинального снижения объемов захоронения твердых коммунальных отходов, европейские страны в своих программах используют собственные технологии и методы. Так, Германия и Нидерланды пошли по пути создания и установки в пунктах образования пластиковых отходов специализированного оборудования, которое размалывает или расплющивает пластиковые емкости. Взамен человек получает монету или талон на приобретение со скидкой товаров, например напитков. В результате в этих странах восстанавливают $60-70 \%$ от общего объема тары из пластического материала.

Швеция лидирует среди европейских государств в области переработки и производства энергии из мусора. На свалки отправляется только 4\% мусора (в среднем по Европе - около 
$38 \%$ ), остальной в результате переработки обеспечивает $20 \%$ объемов центрального отопления. Созданные мощности мусоросжигающих заводов таковы, что страна испытывает дефицит собственного мусора для обеспечения энергетических нужд. Для решения этой проблемы планируется ежегодный импорт 800 тыс. т отходов из других стран, в том числе из соседней Норвегии [3], поскольку сжигание отходов в Норвегии обходится дороже. Образующуюся золу, содержащую тяжелые металлы, предлагается экспортировать обратно в Норвегию.

По оценкам экспертов, со временем ведущим государствам Европы не будет хватать собственного мусора для переработки, и его предполагается импортировать из Италии, Болгарии, Румынии или стран Прибалтики, в которых нет мусороперерабатывающих заводов.

Значительных успехов в области рециклинга добилась Япония, которая по большинству видов сырья и топлива сильно зависит от импорта. Уже к 1985 г. в японской промышленности утилизировалось до 60\% отходов. В 1992 г. в стране был принят закон «О стимулировании использования вторичного сырья», в 1997 г. - «О стимулировании сортировки при сборе и повторном использовании тары и упаковочных материалов». В Японии широко применяется энергетический потенциал твердых коммунальных отходов: сжигается $65 \%$ их объема.

Показателен опыт США: 98\% всего производимого стекла идет в переработку, пластмассовые упаковки пищевых продуктов и напитков разделяются непосредственно на заводах по переработке мусора, на мусоросжигающих заводах утилизируется только $15 \%$ ТКО.

Экологическое право в США играет все более заметную роль в стимулировании производства вторичного сырья из отходов. Захоронение и сжигание отходов с учетом соблюдения всех экологических норм оказывается в три раза дороже переработки.

Кроме того, действует требование к администрациям штатов о закупке продукции вторичной переработки. Во многих из них приняты законы, согласно которым каждый округ под угрозой прекращения финансирования обязан к определенному сроку ввести рециклизацию некоторой части отходов на своей территории. В ряде штатов приняты законы о запрете на отдельные виды упаковок из неразлагающихся компонентов. Вместе с тем 
правительства штатов стремятся оказывать поддержку компаниям, использующим вторичные материалы. Так, в штате Нью-Джерси принят законопроект о 50\%-й скидке по налогу на оборудование, используемое при производстве продукции, содержащей не менее половины вторичных материалов.

\section{Российская практика утилизации отходов}

Масштабы ежегодного образования отходов в России (отходы промышленности, строительства и сельского хозяйства, осадок сточных вод и твердые бытовые отходы жилищно-коммунального хозяйства) исчисляются миллиардами тонн (рисунок). В 2014 г. федеральным законом № 458-Ф3 был введен новый термин: твердые коммунальные отходы (ТКО), которые включают, наряду с бытовыми, отходы, образующиеся в процессе деятельности юридических лиц, индивидуальных предпринимателей, подобные по составу отходам, образующимся в жилых помещениях в процессе потребления физическими лицами [4].

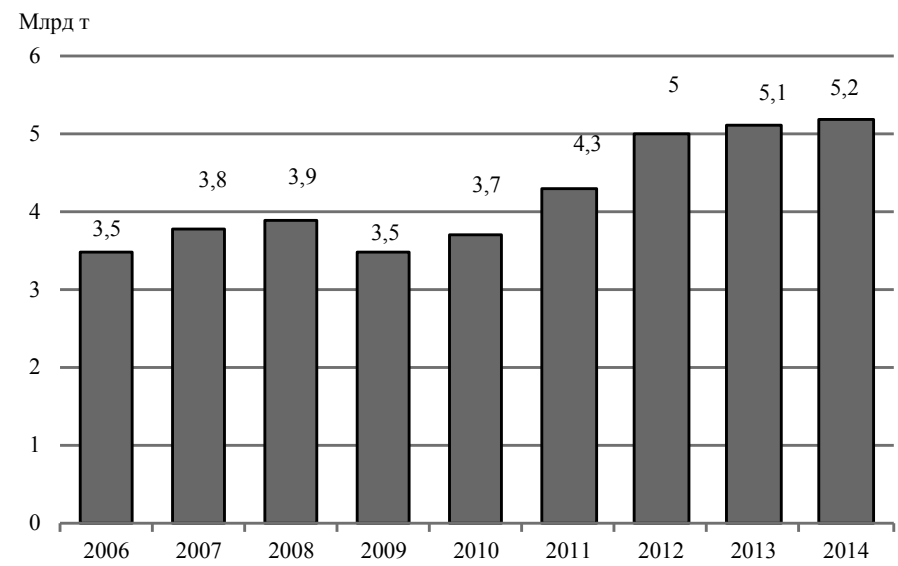

Источник: [5].

Образование отходов в России в 2006-2014 гг., млрд т

В последние годы в РФ ежегодно образуется около 60 млн т твердых коммунальных отходов с годовым приростом 3-4\% [6]. В среднем на человека приходится до 400 кг таких отходов в год [7] (в Европе - 510 кг). Уже к 2025 г. их объем возрастет 
до 500 кг на душу населения, что потребует вдвое увеличить земельные площади для их захоронения [8].

В России для хранения и переработки ТКО используются такие способы, как предварительная сортировка, санитарная земляная засыпка, захоронение на полигонах, сжигание, переработка, биотермическое компостирование. Свыше 90\% ТКО вывозится на полигоны для захоронения, уровень переработки составляет лишь 5-7\%, в то время как в странах ЕС достигает 60\%. Следует отметить, что в России крайне мало полигонов, оборудованных в соответствии с современными требованиями, более половины из них переполнены и не отвечают задачам охраны окружающей среды. В Москве на полигоны отправляют около 93\% ТКО, 3\% утилизируются путем сжигания и только 4\% перерабатываются с выделением вторичного сырья.

В настоящее время мусорными полигонами владеют преимущественно частные компании, арендующие землю у муниципалитетов или приобретающие ее в собственность. Это прибыльный бизнес, который зачастую ведется с нарушениями закона (пропускается больше мусоровозов, захораниваются запрещенные отходы и др.). Так как хранение отходов в полигонах-свалках небезопасно для окружающей среды, они все больше удаляются от города, соответственно, увеличивается плечо вывоза отходов, возрастают расходы на транспортировку. В Европе захоронение на полигоне - это самый дорогой способ утилизации, а в России - самый дешевый - (300-1000 руб./т), в то время как в США - 1000 долл./т [9].

Экологически безопасный полигон для захоронения твердых комунальных отходов - дорогостоящее, технически очень сложное природоохранное сооружение, требующее вывода значительных земельных ресурсов из хозяйственного оборота. В России более 14700 санкционированных мест размещения возрастающих объемов отходов занимают территорию около 4 млн га, и площадь, занятая полигонами, ежегодно увеличивается на 2,5-4\% [10].

Сжигание - наиболее сложный и высокотехнологичный метод утилизации, позволяющий не только втрое уменьшить количество отходов, но еще и получать электроэнергию и тепло.

Для сжигания твердых комунальных отходов с использованием специального оборудования требуется предварительно удалить 
крупные объекты, металлы, а оставшиеся отходы - измельчить. На территории России работают всего семь мусоросжигательных заводов (два из них в Москве, производительностью 120 тыс. т/год каждый), и в их технологических циклах не предусмотрена предварительная сортировка, что приводит к выбросам большого количества вредных веществ [10].

В Европе сжигание считается основным источником загрязнения окружающей среды диоксинами, поэтому на данный способ приходится около 20\% утилизируемых отходов, а в ряде стран (Франция, Великобритания и др.) от него вовсе отказались.

\section{Становление отраслей рециклинга в РФ}

Создание новой системы обращения с отходами в России в середине 1990-х годов было обусловлено ликвидацией прежней системы организации сбора и утилизации отходов и быстрым появлением новых видов и ростом объемов упаковочных материалов. В СССР существовала отлаженная государственная заготовительная система утилизируемых отходов - в производство возвращалось, например, 87\% стеклянных бутылок. В период рыночных преобразований с ликвидацией приемных пунктов и низкими ценами на стеклотару у населения отсутствует мотивация ее утилизации. Доля цены стеклянной упаковки составляет 5-7\% от стоимости продукта, тогда как в советское время она достигала 50\%. Как следствие, например, в Новосибирске перерабатывается лишь 20\% стеклобоя, что в 3-4 раза ниже уровня утилизации в странах Евросоюза. Между тем себестоимость металла, стекла и пластика, произведенных из вторичных ресурсов, в 3-5 раз ниже, чем при получении их из первичного сырья, при этом сохраняется природная среда обитания.

Проблемы сортировки. Основным принципом глубокой комплексной переработки твердых коммунальных отходов является их сортировка с максимальным извлечением вторичного сырья. Современные технологии позволяют вовлекать значительную массу отходов в оборот в качестве вторичного сырья, что обеспечивает сохранение материальных и энергетических ресурсов. Здесь многое зависит от организации работы на стадиях сбора и транспортировки (удаления) муниципальных отходов. Альтернативные методы - переработка отдельных компонентов отходов материалов и биологические - считаются лучшими с точки 
зрения долгосрочного эффекта в охране окружающей среды, снижения количества захоронений отходов. Однако их внедрение напрямую связано с организацией качественного раздельного сбора и сортировки (сепарации) отходов.

Возможны три взаимодополняющих друг друга направления сепарации отходов:

- селективный покомпонентный сбор отходов у населения в местах образования с последующей сортировкой на специальных установках (преимущественно вручную); для извлечения металлов иногда применяется механизированная сепарация;

- селективный пофракционный сбор в местах образования так называемых коммерческих отходов (рынки, магазины, учреждения, школы и др.), с последующим извлечением из них ценных компонентов комбинированными методами ручной и механизированной сортировки (на специальных объектах);

- сортировка в заводских условиях (преимущественно механизированная, в ряде случаев технологическая схема может включать элементы ручной сортировки крупнокусковой фракции отходов).

Следует отметить, что при селективном сборе выход компонентов, поддающихся переработке, намного выше, чем при его отсутствии. Переход России на селективный метод затруднен, так как он требует накопления отходов в домашних контейнерах и установки специальных коммунальных контейнеров во дворах. Основная масса населения согласится на раздельный сбор мусора при условии снижения оплаты за вывоз отходов.

Для решения этой проблемы необходима разработка общефедеральных программ с участием Минэнерго РФ, МинЖКХ и других министерств и ведомств. Важно, чтобы государство обратило внимание на проблему сейчас, а не на критической стадии, когда «мусорный кризис» заставит принимать чрезвычайные меры с привлечением армии и сил МЧС. Так, захоронение твердых бытовых отходов на полигонах и свалках в 1990-2006 гг. в РФ привело к росту выбросов парниковых газов на 53,5\% [5]. Раздельный сбор мусора позволяет вдвое уменьшить массу отходов жилищно-коммунального сектора для захоронения ${ }^{1}$, что

\footnotetext{
${ }^{1}$ По мнению экспертов из Лиги переработчиков макулатуры, из твердых коммунальных отходов можно выделить 55-60\% полезных фракций, только макулатура составляет 30-35\% их массы [11].
} 
способствует сокращению эмиссии парниковых газов на полигонах и улучшению экологической обстановки в регионах.

Решение проблемы промышленной переработки отходов требует масштабных инвестиций с привлечением бизнеса. В последние годы российский рынок мусоропереработки претерпел существенные изменения: он становится конкурентным, бизнес активно приходит в эту сферу. Крупнейшим участником рынка является государственная корпорация «Ростехнологии». Практически во всех регионах работают крупные предпринимательские структуры в сфере переработки отходов. Однако неуверенность в доходности бизнеса обусловлена отсутствием гарантий предпринимателям и инвесторам договорных цен на отходы и поставки отходов в необходимых объемах в среднесрочной перспективе, а также низкими тарифами на переработку и сортировку. По оценкам бизнеса, они должны превышать существующие.

Основная цель преобразований в сфере управления отходами - создание условий для достижения рентабельности бизнеса для каждого участника процесса утилизации отходов на всех этапах рециклинга (раздельный сбор отходов, транспортировка, сортировка, переработка и использование энергетического потенциала).

\section{Государственное управление в сфере ТКО в России}

Основополагающим законом, регулирующим отношения между участниками рынка отходов, является ФЗ № 89 «Закон об отходах производства и потребления» (1998 г.).

Министерство природных ресурсов и экологии РФ разрабатывает единую государственную политику и ведет надзор за исполнением законодательства Российской Федерации. За министерством закреплено право лицензирования деятельности по сбору, использованию, обезвреживанию, транспортированию и размещению отходов. Важной функцией его деятельности является формирование стратегий и методическое обеспечение разработки региональных программ.

Становление комплексной рыночной системы обращения с твердыми коммунальными отходами и отраслей рециклинга сталкивается с институциональными барьерами при формировании 
рынка вторичных отходов, организации вывоза и переработки мусора, а также с противоречиями экономических интересов участников рынка, общества и государства.

Среди основных барьеров следует отметить:

- частые реорганизации в системе управления обращением с отходами;

- низкую преемственность экологических стратегий при смене федерального, областного и муниципального руководства и их управленческих команд;

- высокие риски невыполнения государственных экологических программ в субъектах Федерации;

- высокие инвестиционные риски участия частных предпринимателей в государственных экологических проектах;

- непроработанность механизмов экономического стимулирования извлечения вторичных материалов;

- отсутствие комплексной системы стимулов для фирм, занимающихся раздельным сбором и сортировкой мусора;

- отсутствие в жилищно-коммунальном хозяйстве и у населения навыков и культуры обращения с отходами.

Комплексная «Стратегия обращения с твердыми коммунальными (бытовыми) отходами в Российской Федерации до 2030 г.» (приказ № 298 Минприроды РФ от 14.08.2013 г.) в качестве важнейших целей предусматривает развитие инфраструктуры по раздельному сбору, утилизации, обезвреживанию, экологически безопасному размещению твердых коммунальных отходов (п. 11); постепенный переход от полигонного захоронения к промышленной переработке; создание эффективной системы управления в этой области. В качестве первоочередных задач на среднесрочную перспективу выбраны строительство системы экологически безопасных полигонов и раздельный сбор отходов. В субъектах РФ для реализации Стратегии Минприроды РФ разработаны среднесрочные (до 2016 г.) и долгосрочные (до 2020 г.) программы обращения с отходами производства и потребления, нацеленные на ликвидацию несанкционированных свалок, строительство новых полигонов, соответствующих экологическим стандартам, и увеличение доли утилизации и переработки отходов до 30-40\%. При этом в региональных программах не предусматривалось создание мусоросжигательных заводов, а также использование других термических 
технологий переработки, которые могли бы стать альтернативой строительству новых полигонов для захоронения [12].

Опыт реализации региональных программ показал, что при определенных успехах в части строительства полигонов и борьбы с несанкционированными свалками в целом организация вовлечения отходов в глубокую переработку остается пока малоэффективной: коэффициент использования отходов в качестве вторсырья в 2-2,5 раза ниже, чем в развитых странах мира, крайне медленно внедряется система раздельного сбора отходов. По оценкам экспертов, даже в Москве она заработает только через 5-10 лет [13].

Все еще в стадии формирования находится система управления обращения с отходами, включающая весь комплекс мер, обеспечивающих контроль и управление потоками отходов, информационное сопровождение технологий их обезвреживания, переработки или утилизации вторичных ресурсов.

\section{Экономические механизмы обращения с отходами}

В 2014-2015 гг. в России были предприняты попытки реформирования системы управления обращения с отходами и экологического законодательства на основе адаптации мирового опыта. В соответствии со «Стратегией-2030» в ФЗ № 89 «Закон об отходах производства и потребления» внесены важные поправки: введены экологические сборы с производителей отходов упаковки, прописаны механизмы стимулирования вторичной переработки и развития системы раздельного сбора отходов, а также государственной поддержки предпринимателей (редакция от 29.12.2015):

- предусматривается экономическое стимулирование деятельности предпринимателей и юридических лиц в области раздельного сбора вторичных отходов, внедрения новых технологий, обеспечивающих их сокращение;

- в регионах будут созданы операторы, заключающие договоры с частными структурами на сбор, транспортировку, обезвреживание и утилизацию мусора в каждой группе муниципальных образований и отвечающие за обеспечение непрерывности технологической цепочки; 
- планируется новая система финансовых расчетов управляющих компаний ЖКХ с компаниями, оказывающими услуги по вывозу и переработке мусора;

- изменится порядок формирования тарифа за вывоз мусора для населения (теперь он будет включен в структуру платы за коммунальные услуги по требованиям к расчетам тарифов, определенным Правительством РФ). Так, Минстрой РФ предлагает с 1 января 2017 г. ввести новый коммунальный платеж - «налог на мусор», зависящий от сортировки отходов, а тариф на вывоз сортированных отходов должен быть снижен на эту же величину [14];

- будет введена система лицензирования компаний по транспортировке и переработке мусора.

Для реализации этих мер необходимо было разработать 29 постановлений, касающихся экологических сборов и лицензирования компаний по транспортировке и переработке мусора.

Реализация поправок в Ф3 № 89 с 1 января 2016 г. наглядно продемонстрировала сложившуюся в России принципиальную ущербность администрирования - хроническое запаздывание подготовки нормативно-правовых документов, слабую согласованность во времени действий и решений Министерства природных ресурсов и экологии РФ, Минстроя РФ и Министерства жилищно-коммунального хозяйства РФ. Так, к моменту вступления в силу закона не были разработаны нормативные требования к лицензированию, не утверждены тарифы на сбор и вывоз мусора, а также размер экологических сборов с производителей отходов упаковки. Соответственно, не выданы лицензии компаниям, вывозящим мусор, - стало быть, можно ожидать увеличения в 2-3 раза объемов твердых коммунальных отходов, вывозимых на несанкционированные свалки [15].

России потребуется длительный период времени для становления и эффективного функционирования системы организации раздельного сбора и переработки отходов. Для многих регионов остается актуальным использование экологически чистых технологий сжигания отходов, не требующих глубокой сортировки. Регионы стремятся привлечь апробированные за рубежом инновационные энергетические технологии переработки. Проекты мусоросжигательных заводов есть в Свердловской и Челябинской областях, в Якутске и Пензе. Зарубежные партнеры 
всюду разные: в Новосибирске - корейская компания, в Татарстане и Вологде - немецкие [9]. В Бурятии уже несколько лет обсуждается проект строительства на основе японских технологий теплоэлектространции в г. Улан-Удэ мощностью 10 мВт и стоимостью 130 млн долл. Похожие проекты планируют осуществить в Татарстане и Московской области. В конце 2011 г. в Воскресенске испытали аналогичную американскую установку. Следует отметить, что зарубежные аналоги в 2-3 раза дороже отечественных за счет высокой стоимости установки оборудования и трансферта технологий [16].

В настоящее время Минэнерго РФ выступило с инициативой создания новой подотрасли энергетики на основе использования твердых коммунальных отходов и планирует стимулировать строительство мусоросжигающих заводов по производству электрической и тепловой энергии для оптовых потребителей. Одна из целей на ближайшую перспективу - реализация пилотных проектов по строительству высокотехнологичных генерирующих энергетических объектов мощностью 10 мВт с переработкой 240 тыс. т отходов ежегодно ${ }^{2}$. Сметная стоимость такой электростанции составит не менее 60 млн долл., причем более $65 \%$ стоимости проекта - это затраты на этапах подготовки мусора к сжиганию: создание сортировочной станции, установки по извлечению и очистке биогаза.

\section{$\star \star \star$}

Для наиболее эффективной утилизации и переработки твердых коммунальных отходов в России необходимо создание мусороперерабатывающей отрасли, которая объединила бы весь цикл их утилизации. Развитие промышленных технологий по принципу комбинации различных методов переработки на мусороперерабатывающих заводах обеспечивает малую отходность производства, его максимальную экологичность и экономичность на новой основе сортировки, термообработки, ферментации. Покомпонентная и пофракционная сортировка вдвое сокращает потребность в дорогостоящем термическом и биотермическом

${ }^{2}$ Это эквивалентно объему мусора, производимому городом с населением в полмиллиона человек. 
оборудовании, при этом капитальные затраты на сортировку не превышают $15 \%$ от затрат на термо- и биообработку.

Для организации эффективного взаимодействия предприятий по переработке мусора и рециклинга перспективно формирование системы государственно-частного партнерства в сборе и утилизации ТКО [6]. По нашему мнению, государство должно стать координатором деятельности частного бизнеса по обращению с отходами, так как несет ответственность за состояние окружающей среды, региональные операторы - заниматься организацией и управлением вывозом отходов, а роль частного бизнеса состоит в развитии рентабельных предприятий по вывозу мусора и переработке твердых коммунальных отходов.

\section{Литература}

1. Рециклинг. URL: http://greenevolution.ru/tag/recikling/ (дата обращения: 11.02. 2016).

2. Европа: переработка бумаги превысила 70\%. URL: http://greenevolution.ru/2014/07/03/evropa-pererabotka-bumagi-prevysila-70/ 3. Швеция будет перерабатывать мусор соседних стран. URL: http://greenevolution.ru/2016/02/08/shveciya-budet-pererabatyvatmusor-sosednix-stran/

4. Федеральный закон от 29.12.2014 № 458-ФЗ (ред. от 29.12.2015) «О внесении изменений в Федеральный закон "Об отходах производства и потребления", отдельные законодательные акты Российской Федерации и признании утратившими силу отдельных законодательных актов (положений законодательных актов) Российской Федерации» (с изм. и доп., вступ. в силу с 01.01.2016). URL: http://www.consultant.ru/document/ cons_doc_LAW_172948/

5. Государственный доклад «О состоянии и об охране окружающей среды Российской Федерации в 2014 году». 25 дек. 2015 г. URL: https://www.mnr.gov.ru/regulatory/detail.php? ID=142679 (дата обращения: 22.04.2016).

6. Дмитриев Ю. А., Баранова А. Ф. Сфера обращения с отходами: формирование механизмов и инструментов управления// Региональная экономика: теория и практика. - 2015. - № 36. - С. 46-55. 7. Управление системой сбора, утилизации и переработки твердых бытовых отходов. URL: http://litirus.ru/ekologiya/upravleniesistemoy-sbora-utilizatsii-i-pererabotki-tverdyih-byitovyih-othodov. html 8. Пляскина Н.И., Харитонова В.Н., Вижина И. А. Эколого-экономическая оценка энергетического потенциала утилизации твердых бытовых отходов в регионе // Вестник Новосибирского 
государственного университета. Серия: Социально-экономические науки. - 2013. - Т. 13. Вып. 2. - С. 46-58.

9. Отходный промысел. Как мусор становится индустрией. 22.10.2014. URL: http://zdravkom.ru/factors_san/othodnyj-promyselkak-musor-stanovitsya-industriey

10. Соловьянов А. А. Утилизация отходов в Российской Федерации // Земля против мусора. Российский совет по международным делам. Экология//Аналитика. URL: http://russiancouncil.ru/ inner/?id_4=3558\#top-content (дата обращения: 22.04.2014).

11. Сортировать мусор в России станет выгодно. URL: http:// greenevolution.ru/analytics/sortirovat-musor-v-rossii-stanet-vygodno/ (дата обращения: 11.02. 2016).

12. Пляскина Н.И., Харитонова В.Н., Вижина И. А. Эколого-экономическая оценка использования инновационных технологий для утилизации ТКО // Экологический вестник России. - 2016. № 2. - C. 34-38.

13. URL: http://greenevolution.ru/2016/02/09/sistema-razdelnogosbora-otxodov-zarabotaet-v-moskve-cherez-5-10-let

14. Сортировать мусор в России станет выгодно. URL: http:// greenevolution.ru/analytics/sortirovat-musor-v-rossii-stanet-vygodno/ (дата обращения: 11.02. 2016).

15. Левченко А. Ракурс: “Мусорный” вопрос» на РБК-ТВ 19.11.2015. URL: https://www.facebook.com/ecosystemrussia/videos/1089439331101451/

16. Воздвиженская А. Ищут пути отходам // Российская газета. 2016. - 24 марта. - № 6929 (61). 